\title{
TECNOLOGIAS DIGITAIS E A CONSTRUÇÃO DO CONHECIMENTO CIENTÍFICO: MENSURAÇÃO DE ATITUDES COM GUTTMAN
}

Wender Antônio da Silva ${ }^{a}$ Josefina Barrera Kalhil ${ }^{b}$

\section{A R T I CLE IN F O}

\author{
Palavras chave: \\ Conhecimento Científico; \\ Escala de Guttman; \\ Tecnologias Digitais. \\ E-mail: \\ ${ }^{\mathrm{a}}$ wender.a.silva@gmail.com \\ b josefinabk@gmail.com
}

\author{
R E S U M O
}

\section{INTRODUÇÃO}

Partindo do princípio de que as tecnologias digitais podem e são instrumentos que permitem ao aprendiz uma melhor compreensão da sociedade contemporânea e de como os seres humanos se relacionam nesta sociedade altamente tecnológica, interativa e com uma grande quantidade de ferramentas e de repositórios de informações, percebe-se que ao utilizálas por meio de um planejamento que tenha como fundamentação uma metodologia de ensino que permita e estimule a busca individual por conhecimentos, possibilitando ao acadêmico a visualização, simulação, interação com os mais diversos conceitos da área de ciências por meio de dispositivos computacionais é possível que a construção do conhecimento científico seja promovida e/ou estimulada pela utilização das tecnologias digitais no processo ensinoaprendizagem.

Neste sentido, fundamenta-se nos conceitos de ciencias definidos por Kuhn, Carrilho e Esteban, onde Kuhn (2006) entende que o conhecimento científico somente evolui quando rompe com as tradições dominantes e abre-se ao novo, sendo esta capacidade de regeneração e demarcação de um conhecimento realmente de natureza científica. 
Na mesma linha de raciocínio, Carrilho (1991) destaca que em cada momento histórico da humanidade o homem refletia sobre o seu meio a partir dos meios e condições intelectuais que dispunha naquele instante. O conhecimento humano passou sucessivamente por três estados: teológico, metafísico e científico, ou seja, três métodos de filosofar, sendo que o primeiro é o ponto de partida, o segundo é transitório e o terceiro definitivo.

Já Esteban (2010) afirma que são quatro perspectivas contemporâneas sobre o conhecimento científico: indutivismo, racionalismo crítico, contextualismo e relativismo. Todas elas possuem impacto sobre as práticas de pesquisa no âmbito da educação. Assim, Kuhn (2006) afirma que a história da ciência evolui em ciclos, alguns normais e outros de revolução científica, sendo que a ciência se constrói dentro do paradigma na qual ela e o pesquisador estão inseridos.

Neste sentido, concordamos que em cada época há um conjunto de saberes que permitem fazer esta ou aquela leitura da realidade à qual estamos submetidos (KUHN, 2006). Assim, no século XXI, qual conjunto de saberes permite que consigamos realizar a leitura da realidade a qual estamos imersos? Vivemos em um mundo altamente tecnológico e, em constante evolução, em que ter um smartphone conectado a internet é uma necessidade básica. Neste novo cenário, onde imperam as tecnologias digitais e suas muitas faces (internet, aplicativos, redes sociais, mensageiros e etc), existe uma quantidade incalculável de informações disponíveis, sejam informações úteis e fidedignas, sejam informações falsas, tais como as recentes "Fake News". Neste contexto, percebe-se que o conhecimento e as informações disponíveis na rede mundial de computadores, ficam voláteis cada vez mais rápido, gerando dificuldades para as pessoas filtrarem essa enorme massa de dados. Diante de toda essa dinâmica, muda-se a forma de fazer pesquisa, de realizar a divulgação científica e, também de obter subsídios para a construção do conhecimento científico.

Quando Kuhn (2006, p.21) destaca que "talvez a ciência não se desenvolva pela acumulação de descobertas e invenções individuais" contribui para a afirmação de que as habilidades em tecnologias digitais podem auxiliar na construção do conhecimento científico, tendo em vista que, neste século, a interatividade e o trabalho colaborativo por meio de dispositivos computacionais, são elementos cada vez mais presentes em nosso cotidiano, inclusive no processo ensino-aprendizagem. Destaca-se também que apenas ter acesso aos conhecimentos e as informação não gera a construção do conhecimento científico, pois a ciência 


\section{REVISTA REAMEC}

Revista ta Rede Amazonitica de Eduraçäo

em Ciências e Matemática
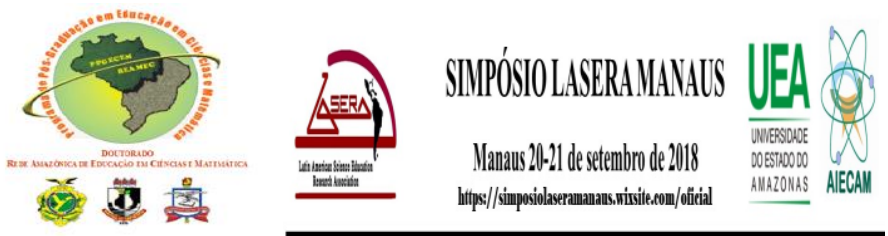

não é o acúmulo gradual de conhecimentos, mas é a complexa relação entre teorias, dados e paradigmas (KUHN, 2006).

Neste cenário, muda-se as perspectivas das interações, pois a cada dia incorporamos novas e múltiplas possibilidades de interação e, neste sentido, a construção do conhecimento científico pode ocorrer por meio de novas dimensões conceituais, não mais centradas em interações lineares, mas sim, de interações não-lineares que se caracterizam basicamente pelo fato de não ser possível prever o resultado de um fenômeno apenas tendo como base a causa a que o mesmo é submetido (PRETTO, 2017).

Neste sentido, percebe-se que, na visão de Prensky (2001) e Moran (2013) neste século, principalmente os jovens, possuem uma visão de mundo diferente, que influencia diretamente na sua formação cultural, na forma de agir, pensar, se relacionar e, claro, na forma como entendem a educação e a construção do conhecimento científico. Podemos afirmar então que, a geração "digital" é caracterizada pela naturalidade com que lidam com os mais diversos tipos de tecnologia digital, bem como, da forma como se relacionam por meio destas.

Neste sentido, este artigo científico visa realizar uma pesquisa com os alunos dos cursos de licenciatura em ciências (biologia, física, química e matemática) de uma universidade pública do estado de Roraima, com o objetivo de verificar a percepção dos mesmos sobre a possibilidade da construção do conhecimento científico por meio de metodologias que utilizam as tecnologias digitais no processo ensino-aprendizagem.

\section{METODOLOGIA}

Esta pesquisa científica utiliza-se da abordagem de pesquisa qualitativa, com foco na coleta de dados por meio do questionário baseado em Guttman e análise de dados utilizando-se da técnica de Cornell ou escalograma. Este tipo de questionário visa mensurar a atitude dos sujeitos em relação a algum tema, objeto ou questão social e, em nosso caso, seria verificar a atitude dos acadêmicos em relação as tecnologias digitais para a construção do conhecimento científico. Assim, Guttman (1944) desenvolveu esta técnica para medir atitudes em uma única dimensão. Este tipo de escala é constituída por afirmações que medem uma única dimensão, ou seja, é uma escala de "unidimensionalidade" e, é caracterizada por medir a intensidade da atitude. Neste sentido, é cumulativa, já que a resposta afirmativa sucessiva inclui a afirmação 
nas anteriores. Destaca-se que trata-se de um método matemático que inicialmente foi aplicado nas áreas de economia, estatística, psicologia e saúde.

Logo, para esta verificação, utilizou-se da classificação itemizada ou escala numérica não-comparativa que, neste caso, apresenta números ou descrições sucintas associadas, ordenadas e bem definidas de acordo com a posição da categoria na escala e, neste sentido, a hierarquização de Guttman utilizada nesta pesquisa pode ser observada no quadro I

\begin{tabular}{|c|c|c|c|}
\hline Item & Questionamento & Sim & Não \\
\hline 01) & $\begin{array}{l}\text { As tecnologias digitais proporcionam facilidades que auxiliam na } \\
\text { construção do conhecimento científico?. }\end{array}$ & & \\
\hline 02) & $\begin{array}{l}\text { Habilidades em Tecnologias Digitais de Informação e } \\
\text { Comunicação são necessárias no atual contexto educacional e da } \\
\text { sociedade do século XXI?. }\end{array}$ & & \\
\hline 03) & $\begin{array}{l}\text { As mídias digitais (vídeos, imagens, simulações) facilitam a } \\
\text { contextualização dos conteúdos, auxiliando a construção do } \\
\text { conhecimento científico? . }\end{array}$ & & \\
\hline 04) & $\begin{array}{l}\text { A interação por meio dos dispositivos de tecnologia digital } \\
\text { permitem a troca de informações que podem levar a construção } \\
\text { do conhecimento cientifico?. }\end{array}$ & & \\
\hline 05) & $\begin{array}{l}\text { A tecnologia digital pode ser considerada uma linguagem da qual } \\
\text { os jovens mais se utilizam nos dias atuais?. }\end{array}$ & & \\
\hline
\end{tabular}

Quadro I: Adaptação da hierarquização de Guttman.

Fonte: Silva e Kalhil (2018) adaptado de Abdi (2010)

Para aplicação do questionário Guttman junto aos acadêmicos dos cursos de ciências, optou-se pelas turmas localizadas no campus de Boa Vista/RR. Assim, o levantamento realizado junto ao Registro Acadêmico da universidade demostrou que existe um universo possível de 198 acadêmicos distribuídos em quatro cursos e oito turmas, conforme demostra a tabela 1 .

Tabela 1: Universo do recorte da pesquisa

\begin{tabular}{|c|c|c|c|}
\hline \multicolumn{4}{|c|}{ CURSOS DE CIÊNCIAS 2018.1} \\
\hline $\mathbf{N}^{\mathbf{o}}$ & Curso de Licenciatura & Semestre & $\begin{array}{l}\text { Acadêmicos } \\
\text { Matriculados }\end{array}$ \\
\hline \multirow{3}{*}{1} & \multirow{3}{*}{ Ciências Biológicas } & $1^{\circ}$ & 31 \\
\hline & & $3^{\circ}$ & 26 \\
\hline & & $6^{\circ}$ & 22 \\
\hline \multirow{2}{*}{2} & \multirow{2}{*}{ Física } & $1^{\circ}$ & 27 \\
\hline & & $5^{\circ}$ & 16 \\
\hline \multirow[b]{2}{*}{$\mathbf{3}$} & \multirow{2}{*}{ Química } & $3^{\circ}$ & 13 \\
\hline & & $5^{\circ}$ & 24 \\
\hline 4 & Matemática & $3^{0}$ & 39 \\
\hline
\end{tabular}

Revista REAMEC, Cuiabá - MT, V. 6, n. Especial, dez 2018, ISSN: 2318-6674

Revista do Programa de Doutorado da Rede Amazônica de Educação em Ciências e Matemática http://periodicoscientificos.ufmt.br/ojs/index.php/reamec 
Revista ta Rete Amazônite de Eduração em Ciências e Matemática
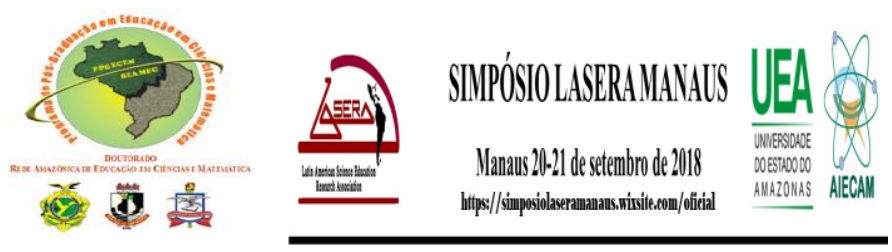

\begin{tabular}{c|c}
\hline TOTAL & 198 \\
\hline Fonte: Registro Acadêmico (2018)
\end{tabular}

Fonte: Registro Acadêmico (2018)

Entendendo que os acadêmicos "calouros" não possuem maturidade suficiente para realizar a pesquisa, bem como ainda não possuem vivência acadêmica que permita entender, em nosso ponto de vista, com clareza os conceitos relacionados a conhecimento científico e as tecnologias digitais, optou-se por excluí-los do universo da amostra e, neste sentido o universo ficou definido com 140 sujeitos. Utilizou-se da amostra não probabilística por conveniência, na qual aplicamos os questionários com os acadêmicos presentes em uma determinada turma e que se dispusessem em realizar a entrevista, conforme apresenta-se na tabela 2.

Tabela 2: Amostra do recorte da pesquisa

CURSOS DE CIÊNCIAS 2018.1

\begin{tabular}{|c|c|c|c|c|}
\hline $\mathbf{N}^{\mathbf{0}}$ & Curso de Licenciatura & Semestre & $\begin{array}{c}\text { Acadêmicos } \\
\text { Entrevistados }\end{array}$ & $\begin{array}{l}\text { Data de Coleta } \\
\text { dos dados }\end{array}$ \\
\hline \multirow{2}{*}{1} & \multirow{2}{*}{ Ciências Biológicas } & $3^{\circ}$ & 18 & $26 / 03 / 2018$ \\
\hline & & $6^{\circ}$ & 15 & 27/03/2018 \\
\hline 2 & Física & $5^{\circ}$ & 10 & 28/03/2018 \\
\hline \multirow{2}{*}{3} & \multirow{2}{*}{ Química } & $3^{\circ}$ & 05 & $02 / 04 / 2018$ \\
\hline & & $5^{\circ}$ & 10 & $03 / 04 / 2018$ \\
\hline 4 & Matemática & $3^{\circ}$ & 18 & $04 / 04 / 2018$ \\
\hline \multicolumn{3}{|c|}{ AMOSTRA } & 76 & - \\
\hline \multicolumn{3}{|c|}{$\begin{array}{l}\text { Porcentagem em relação ao universo de } 140 \\
\text { sujeitos }\end{array}$} & $54,3 \%$ & \\
\hline
\end{tabular}

$\mathrm{Na}$ amostragem analisada, observa-se um percentual maior da área de ciências biológicas em relação as demais áreas. Conforme observa-se no gráfico 1, matemática, química e física totalizam $57 \%$, enquanto ciências biológicas configura-se com $43 \%$.

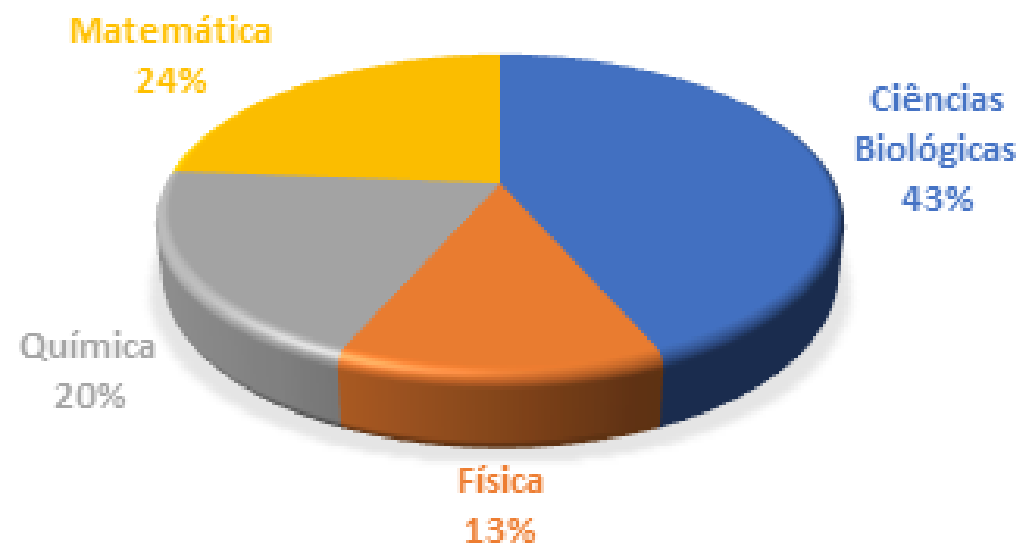

Revista REAMEC, Cuiabá - MT, V. 6, n. Especial, dez 2018, ISSN: 2318-6674

Revista do Programa de Doutorado da Rede Amazônica de Educação em Ciências e Matemática http://periodicoscientificos.ufmt.br/ojs/index.php/reamec 
Revista ta Rete Amazônite de Eduração
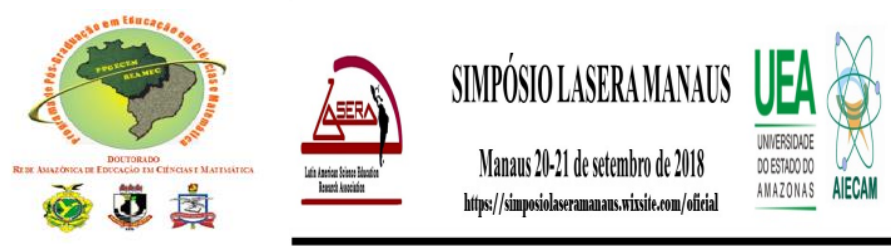

Gráfico 1 - Participantes de Guttman por curso

Fonte: Silva e Kalhil (2018)

Conforme observa-se na figura 1, o cálculo do software "Decision Analyst STATS $^{\mathrm{TM}} 2.0$ " define que para um universo de 140 sujeitos, com uma margem de erro de $8 \%$ e um nível de confiança de 95\%, uma amostra válida seria de 72 acadêmicos. Logo, ressalta-se que a amostra selecionada foi de 76 sujeitos, sendo portanto, uma amostra estatisticamente válida.
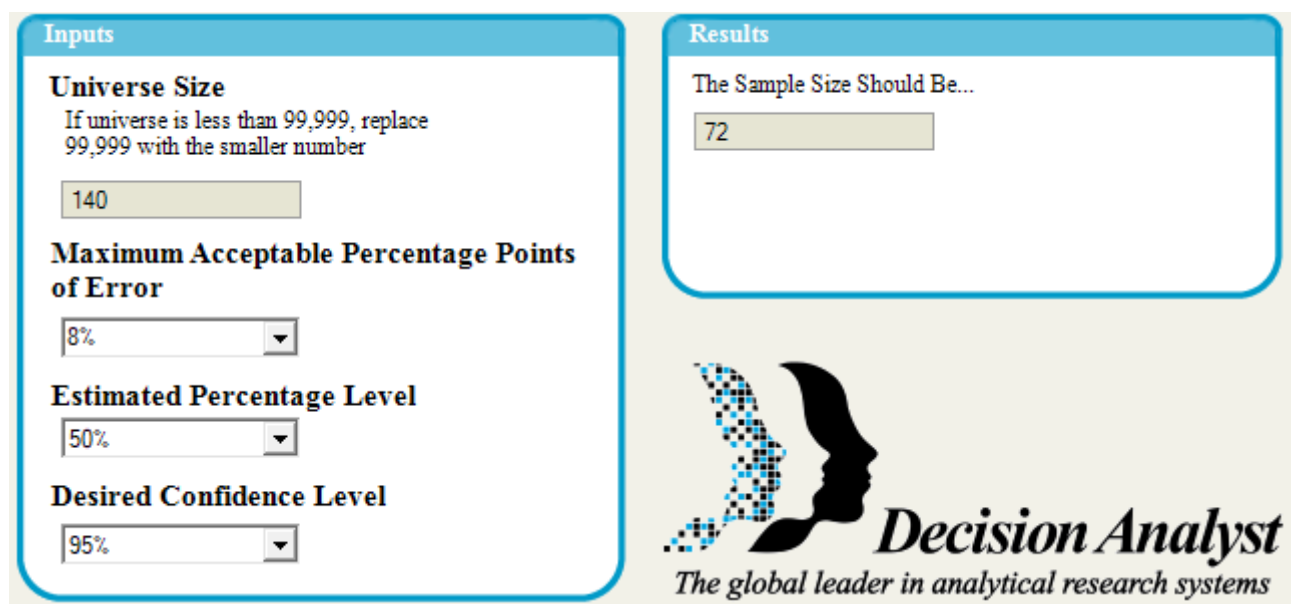

Figura 1 - Cálculo da amostra probabilística simples: alunos participantes de Guttman Fonte: Silva e Kalhil (2018)

\section{RESULTADOS E DISCUSSÃO}

Buscou-se verificar as atitudes, ou seja, de que forma os acadêmicos reagem negativa ou positivamente a respeito das afirmativas colocadas a eles sobre como as tecnologias digitais podem auxiliar a construção do conhecimento científico no processo ensino-aprendizagem de ciências. Assim, entende-se que as atitudes possuem três componentes: cognitivo, afetivo e comportamental. Percebe-se que para este questionário, verifica-se a crença de um sujeito em relação à possibilidade das tecnologias digitais contribuírem de forma positiva, ou não, com a construção do conhecimento científico, configurando-se então, atitude cognitiva. Após a coleta de dados, definiu-se a codificação para a tabulação destes, onde o valor 1 (um) com a cor verde representa a resposta "sim" e o valor 0 (zero) com a cor vermelha representa a resposta "não". Para preservar a identidade dos sujeitos, criamos códigos que remetem à quantidade de itens, curso e semestre coletados, conforme demonstrado no quadro II. 


\begin{tabular}{|l|l|l|}
\hline Sujeitos & Curso & Semestre \\
\hline 1Q3 à 5Q3 & Licenciatura em Química & $3^{\circ}$ semestre \\
\hline 6M3 à 23M3 & Licenciatura em Matemática & $3^{\circ}$ semestre \\
\hline 24B3 à 41B3 & Licenciatura em Ciências Biológicas & $3^{\circ}$ semestre \\
\hline 42Q5 à 51Q5 & Licenciatura em Química & $5^{\circ}$ semestre \\
\hline 52F5 à 61F5 & Licenciatura em Física & $5^{\circ}$ semestre \\
\hline 62B6 à 76B6 & Licenciatura em Ciências Biológicas & $6^{\circ}$ semestre \\
\hline
\end{tabular}

Quadro II - Distribuição de sujeitos por curso/semestre

Fonte: Silva e Kalhil (2018)

Observa-se que para os quadros III e IV deixamos somente as linhas onde os sujeitos responderam "não" em alguma das questões apresentadas, sendo que para as demais linhas suprimidas, entende-se que, foram respondidas todas com "sim".

\begin{tabular}{|c|c|c|c|c|c|c|c|}
\hline \multirow{2}{*}{ Qtd } & \multirow{2}{*}{ Sujeitos } & \multicolumn{5}{|c|}{ Questões } & \multirow{2}{*}{$\begin{array}{l}\text { Total de "sim" por } \\
\text { sujeito }\end{array}$} \\
\hline & & 1 & 2 & 3 & 4 & 5 & \\
\hline 1 & 1Q3 & 1 & 1 & 1 & 1 & 0 & 4 \\
\hline 6 & $6 \mathrm{M} 3$ & 1 & 1 & 1 & 0 & 1 & 3 \\
\hline 7 & $7 \mathrm{M} 3$ & 1 & 1 & 1 & 0 & 1 & 3 \\
\hline 9 & 9M3 & 1 & 0 & 1 & 1 & 1 & 4 \\
\hline 15 & $15 \mathrm{M} 3$ & 1 & 1 & 1 & 1 & 0 & 4 \\
\hline 17 & $17 \mathrm{M} 3$ & 1 & 1 & 1 & 0 & 1 & 3 \\
\hline 18 & $18 \mathrm{M} 3$ & 1 & 1 & 1 & 1 & 0 & 4 \\
\hline 26 & $26 \mathrm{~B} 3$ & 1 & 1 & 1 & 1 & 0 & 4 \\
\hline 29 & 29B3 & 1 & 1 & 0 & 1 & 1 & 4 \\
\hline 44 & 44Q5 & 0 & 0 & 1 & 1 & 0 & 2 \\
\hline 55 & $55 \mathrm{~F} 5$ & 1 & 1 & 1 & 1 & 0 & 4 \\
\hline \multicolumn{2}{|c|}{ Total de "sim" por questão } & 75 & 74 & 75 & 73 & 70 & 367 \\
\hline
\end{tabular}

Partindo do quadro III, observa-se na literatura que a maneira mais conhecida de analisar as questões ou afirmações para desenvolver a escala de Guttman é a técnica de Cornell, ou Escalograma (GUTTMAN, 1947) . Neste sentido classificou-se os sujeitos de acordo com a pontuação total, ou seja, da pontuação mais alta para a pontuação mais baixa, verticalmente para baixo; em um segundo momento, classificou-se afirmações (questões) de acordo com sua intensidade, ou seja, do maior para o menor e da esquerda para a direita. Neste sentido, podese observar o quadro IV, onde as pontuações dos assuntos ordenados são cruzadas com os itens e suas categorias hierárquicas.

\begin{tabular}{|c|c|c|c|c|c|c|c|}
\hline \multirow{2}{*}{ Qtd } & \multirow{2}{*}{ Sujeitos } & \multicolumn{5}{|c|}{ Questões } & \multirow{2}{*}{$\begin{array}{c}\text { Total de "sim" por } \\
\text { sujeito }\end{array}$} \\
\hline & & 1 & 3 & 2 & 4 & 5 & \\
\hline 1 & 1Q3 & 1 & 1 & 1 & 1 & 0 & 4 \\
\hline 6 & $6 \mathrm{M} 3$ & 1 & 1 & 1 & 0* & $1 *$ & 4 \\
\hline
\end{tabular}

Revista REAMEC, Cuiabá - MT, V. 6, n. Especial, dez 2018, ISSN: 2318-6674

Revista do Programa de Doutorado da Rede Amazônica de Educação em Ciências e Matemática http://periodicoscientificos.ufmt.br/ojs/index.php/reamec 
Revista ta Rede Amazonitica de Eduraçäo
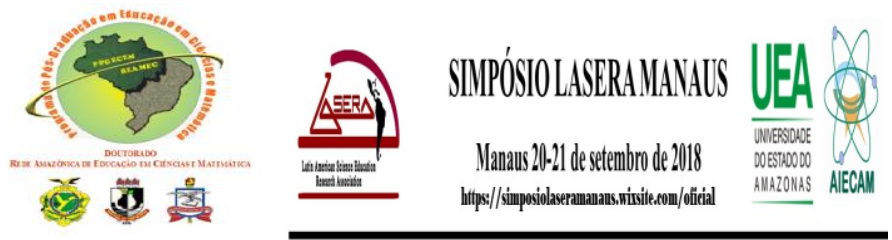

\begin{tabular}{|c|c|c|c|c|c|c|c|}
\hline 7 & $7 \mathrm{M} 3$ & 1 & 1 & 1 & $0^{*}$ & $1^{*}$ & 4 \\
\hline 9 & $9 \mathrm{M} 3$ & 1 & 1 & $0 *$ & 1 & $1^{*}$ & 4 \\
\hline 15 & $15 \mathrm{M} 3$ & 1 & 1 & 1 & 1 & 0 & 4 \\
\hline 17 & $17 \mathrm{M} 3$ & 1 & 1 & 1 & $0^{*}$ & $1^{*}$ & 4 \\
\hline 18 & $18 \mathrm{M} 3$ & 1 & 1 & 1 & 1 & 0 & 4 \\
\hline 26 & $26 \mathrm{~B} 3$ & 1 & 1 & 1 & 1 & 0 & 4 \\
\hline 29 & $29 \mathrm{~B} 3$ & 1 & $0^{*}$ & 1 & 1 & $1^{*}$ & 4 \\
\hline 55 & $55 \mathrm{~F} 5$ & 1 & 1 & 1 & 1 & 0 & 4 \\
\hline 44 & $44 \mathrm{Q} 5$ & $0 *$ & 1 & $0 *$ & $1 *$ & 0 & 2 \\
\hline \multicolumn{2}{|c|}{ Total de "sim" por questão } & $\mathbf{7 5}$ & $\mathbf{7 5}$ & $\mathbf{7 4}$ & $\mathbf{7 3}$ & $\mathbf{7 0}$ & Total geral de erros \\
\hline \multicolumn{2}{|c|}{ Número de erros por questão } & $\mathbf{1}$ & $\mathbf{1}$ & $\mathbf{2}$ & $\mathbf{3}$ & $\mathbf{6}$ & $\mathbf{1 3}$ \\
\hline
\end{tabular}

Quadro IV- Dados ordenados conforme técnica de Escalograma

Fonte: Silva e Kalhil (2018)

Observa-se que no quadro IV, os valores destacados com (*) asterisco são, segundo García (2013), considerados erros do Escalograma. Assim, percebe-se que os sujeitos constituem as linhas e as categorias dos itens que formam as colunas, dando-nos condições de analisar o número de erros ou quebras no padrão de intensidade da escala. Neste sentido, destaca-se que um erro ou ruptura é uma inconsistência nas respostas de um sujeito em uma escala, ou seja, é uma ruptura com o padrão de intenção de escala ideal.

Então, a análise foi baseada na detecção dos erros, estabelecendo pontos de corte onde as afirmações e suas categorias são cruzadas e, somando-se as afirmações onde nenhuma inconsistência é encontrada. Neste sentido, quando o número de erros é excessivo, a escala não mostra reprodutibilidade e não pode ser aceita. Logo, a reprodutividade ideal ocorre quando não existe quebra do padrão de intensidade da escala.

Para Guttman (1950) existe reprodutibilidade se, a partir da pontuação total de cada sujeito, pudermos reproduzir sua pontuação em cada item e, existe escalabilidade se os itens tiverem intensidade diferente e puderem representar diferentes graus de atitude. Assim, ambas as características estão relacionadas e assumem que os itens são unidimensionais, ou seja, que medem uma única dimensão.

Desta forma, Torres $(2009$, p. 33$)$ destaca que "a escala será válida para determinar a amostra se o total de erros encontrados for pequeno diante do número total de respostas", conforme equação 1 .

$$
\text { Proporção de erros }(\mathbf{0}, \mathbf{0 3})=\frac{\text { Total de erros }(\mathbf{1 3})}{\text { Total de respostas }(\mathbf{7 6} * \mathbf{5})}
$$

Equação 1 - Proporção de erros.

Fonte: Silva e Kalhil (2018) adaptado de Torres (2009) 


\section{REVISTA REAMEC}

Revista ta Rede Amazonitica de Eduraçäo

em Ciências e Matemática

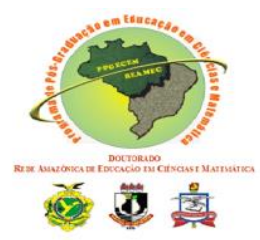

Ao analisarmos a equação 1, observa-se que o coeficiente para proporção de erros está em 0,03 ou seja, $3 \%$ de erro em relação ao universo de respostas.

Torres (2009, p.33) afirma que "para determinação da validade do escalonamento construído, calcula-se o Coeficiente de Reprodutividade (CR)", conforme apresentado na equação 2.

$$
\mathrm{CR}\left(\mathbf{0 , 9 7 )}=1-\frac{\text { Total de erros }(\mathbf{1 3})}{\text { Total de respostas }(\mathbf{7 6} * \mathbf{5})}\right.
$$

Equação 2 - Coeficiente de Reprodutividade

Fonte: Silva e Kalhil (2018) adaptado de Abdi (2010)

Torres (2009, p.33) destaca que

O coeficiente de Reprodutibilidade consiste em uma mensuração do grau relativo de adequação com que é obtida a ordem de distribuição dos itens em uma escala para que esta atenda aos padrões de distribuição de uma escala ideal. É garantido contando-se o número de respostas que não cumprem a lógica prevista pela escala para cada pessoa ("erros"), dividindo-se esses erros pelo número total de respostas e subtraindo-se "1" da fração resultante (TORRES, 2009, p. 33).

Um coeficiente de Reprodutibilidade (CR) $\geq 0,9(90 \%)$ é considerado ideal pois o erro será $\leq 10 \%$, ou seja, somente $10 \%$ ou menos de erros aconteceram na amostra, proporção essa considerada pequena diante dos acertos (TORRES, 2009, p.33-34). Neste sentido, observamos que o CR da escala proposta é de 0,97 o que para Guttman (1950), Torres (2009) e Abdi (2010) confirma sua validade.

Torres $(2009$, p. 35) relata que

Além do Coeficiente de Reprodutividade, o nível de confiabilidade e, portanto, a validação de um escalonamento feito pelo método de Guttman (1944) pode ser avaliado por meio do Coeficiente de Escalabilidade e da Reprodutibilidade Marginal Mínima (TORRES, 2009, p. 35).

A Reprodutibilidade Marginal Mínima (RMM) é um auxiliar de cálculo, um qualificador do Coeficiente de Reprodutividade. Torres (2009) destaca que RMM representa o menor coeficiente de reprodutibilidade que é possível obter dadas as respostas observadas.

$$
\operatorname{RMM}(\mathbf{0}, \mathbf{9 7})=\frac{\text { Total de Respostas }(\mathbf{5} * \mathbf{7 6})-\text { Erros por linha }(\mathbf{1 3})}{\text { Total de Respostas }(\mathbf{5} * \mathbf{7 6})}
$$

Equação 3 - Reprodutibilidade Marginal Mínima.

Fonte: Silva e Kalhil (2018) adaptado de García (2013) 


\section{REVISTA REAMEC}

Revista ta Rede Amazonitica de Eduraçäo

em Ciências e Matemática

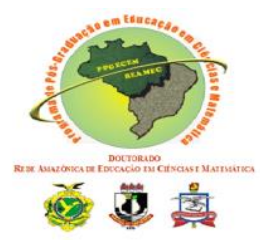

Torres (2009) destaca que os cálculos auxiliares, tais como a Porcentagem de Melhora (PM) e a Porcentagem de Melhora Possível (PMP) permitem uma melhor leitura da realidade por meio da ordenação proposta por Guttman (1950).

$$
\operatorname{PM}(\mathbf{0}, \mathbf{0})=\mathrm{CR}(\mathbf{0}, \mathbf{9 7})-\operatorname{RMM}(\mathbf{0}, \mathbf{9 7})
$$

Equação 4 - Porcentagem de Melhora.

Fonte: Silva e Kalhil (2018) adaptado de Torres (2009)

$$
\operatorname{PMP}(\mathbf{9 9}, 03)=100-\operatorname{RMM}(\mathbf{0}, \mathbf{9 7})
$$

Equação 5 - Porcentagem de Melhora Possível.

Fonte: Silva e Kalhil (2018) adaptado de Torres (2009)

A Porcentagem de Melhora (PM) é calculada subtraindo-se a Reprodutibilidade Marginal Mínima do Coeficiente de Reprodutibilidade, sendo que a Porcentagem de Melhora Possível (PMP) é calculada subtraindo-se o RMM do CR ideal (100\%) (TORRES, 2009).

Já o Coeficiente de Escalabilidade (CE) é uma medida do máximo por cento da reprodutibilidade associado à escalabilidade após o ajuste da assimetria dos dados. Coeficientes com valores $\geq 60 \%$ representam a melhor leitura da realidade por meio da ordenação proposta por Guttman (NUNES, 2015).

$$
\text { CE }(\mathbf{1})=1-\frac{\text { Erro Escalograma (13) }}{\text { Erros por linha (13) }}
$$

Equação 6 - Coeficiente de Escalabilidade. Fonte: Silva e Kalhil (2018) adaptado de García (2013)

Ao analisar os coeficientes de Percentual de Melhora e o Percentual de Melhora Possível, percebe-se valores positivos (baixos) em relação à necessidade de melhoria da escala utilizada. Partindo-se do princípio de Guttman (1950) o escalograma utilizado nesta pesquisa possui excelente escalabilidade ao apresentar coeficiente 1 (um), ou seja, $100 \%$.

Na tabela 3 apresenta-se o Escalonamento de Guttman relacionada ao entendimento de que as tecnologias digitais podem auxiliar na construção do conhecimento científico nos cursos de ciências. Observa-se que a escala mostrou-se perfeitamente válida, com CR e CE dentro dos padrões ideais para o método Guttman. 
Tabela 3 - Hierarquização do entendimento tecnologias digitais e construção do conhecimento científico nos cursos de ciências.

\begin{tabular}{l|c|c}
\multicolumn{1}{c|}{\begin{tabular}{c}
\multicolumn{1}{c|}{$\begin{array}{c}\text { Questionamentos } \\
\text { CR: 0,97 } \\
\text { CE: 1 }\end{array}$} \\
\cline { 2 - 3 }
\end{tabular}} & \multicolumn{2}{c}{ Sim Não } \\
\hline $\begin{array}{l}\text { As tecnologias digitais proporcionam facilidades que auxiliam na } \\
\text { construção do conhecimento científico? }\end{array}$ & 98,7 & 1,3 \\
\hline $\begin{array}{l}\text { Habilidades em Tecnologias Digitais de Informação e Comunicação são } \\
\text { necessárias no atual contexto educacional e da sociedade do século } \\
\text { XXI?. }\end{array}$ & 98,7 & 1,3 \\
\hline $\begin{array}{l}\text { As mídias digitais (vídeos, imagens, simulações) facilitam a } \\
\text { contextualização dos conteúdos, auxiliando a construção do } \\
\text { conhecimento científico? }\end{array}$ & 97,4 & 2,6 \\
\hline $\begin{array}{l}\text { A interação por meio dos dispositivos de tecnologia digital permitem a } \\
\text { troca de informações que podem levar a construção do conhecimento } \\
\text { cientifico?. }\end{array}$ & 96,1 & 3,9 \\
\hline $\begin{array}{l}\text { A tecnologia digital pode ser considerada uma linguagem da qual os } \\
\text { jovens mais se utilizam nos dias atuais?. }\end{array}$ & 88,2 & 11,8 \\
\hline Totais & $\mathbf{9 5 , 8 \%}$ & $\mathbf{4 , 2 \%}$ \\
\hline
\end{tabular}

Fonte Silva e Kalhil (2018)

Observa-se que não existe grande diferença ou variações nas respostas, concentrandose de forma bem acentuada na confirmação das questões. Percebe-se também que o item com mais questões negativas é o que trata das tecnologias digitais como uma linguagem da qual os jovens mais se utilizam nos dias atuais, conforme demonstrado no gráfico 2.

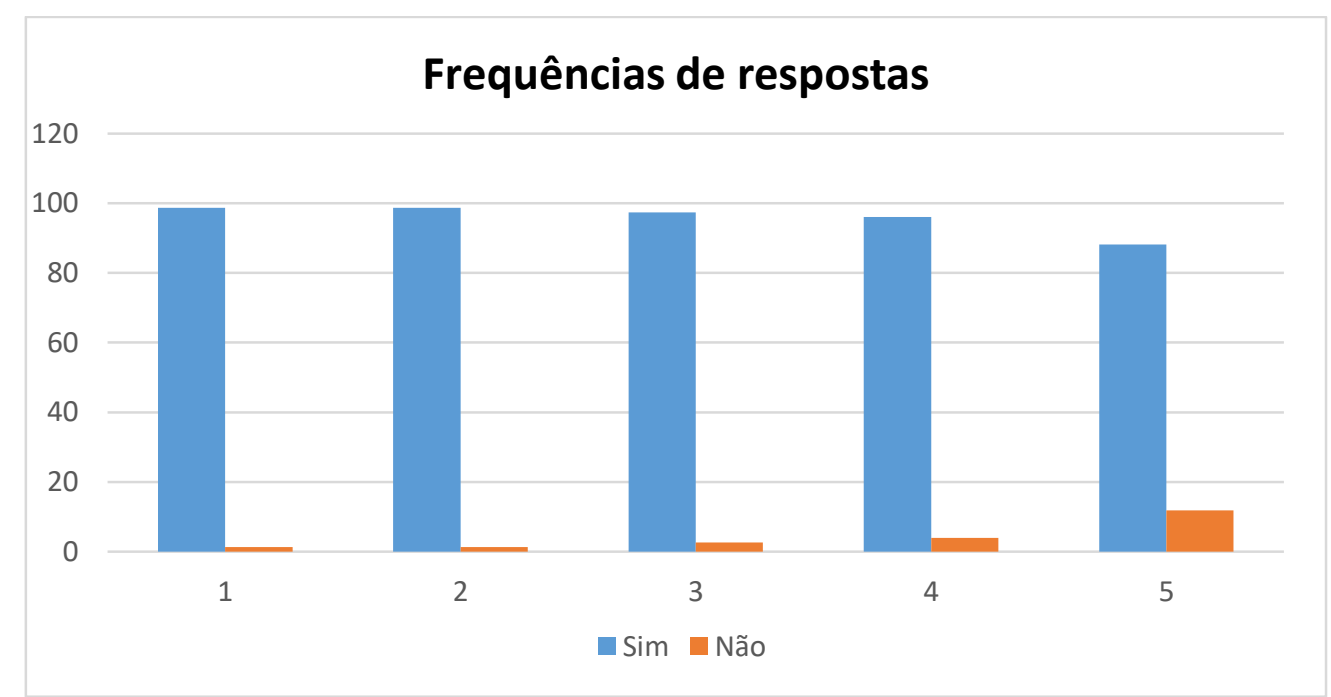

Gráfico 2 - Frequências das repostas dos sujeitos

Fonte: Silva e Kalhil (2018)

\section{CONCLUSÃO}

Ao se analisar a proporção de respostas positivas em relação ao tema investigado, levando-se em consideração a hierarquização do entendimento sobre as tecnologias digitais e a 


\section{REVISTA REAMEC}

Revista ta Rede Amazonitica de Eduraçäo

em Ciências e Matemática

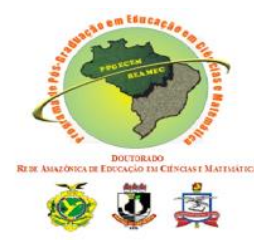

relação com a construção do conhecimento científico nos cursos de ciências, do qual utilizouse da metodologia de Guttman para colega e análise de dados, podemos perceber que não há distorções relevantes nos coeficientes de reprodutibilidade e escalabilidade, validando-se a percepção investigada. Percebe-se claramente que os resultados e a atitude dos sujeitos investigados são compatíveis e caminham na mesma direção do referencial teórico de que trata a temática, ou seja, existe a crença nos acadêmicos de que as tecnologias digitais devem fazer parte do processo ensino-aprendizagem e que estas podem promover ou auxiliar na construção do conhecimento científico. Neste sentido confirmou-se a crença dos acadêmicos de que as tecnologias digitais podem sim, auxiliar na construção do conhecimento científico. Destacamos que a validade do questionário se deu pela análise realizada em Guttman que retornou-nos Coeficiente de Reprodutividade de $97 \%$ e Coeficiente de Escalabilidade de 100\%, onde o percentual de erro do questionário ficou em $3 \%$.

Por fim, conclui-se nesta pesquisa científica que a utilização das tecnologias digitais, por meio de metodologias específicas, utilizando-se de objetos de aprendizagem que permitem a visualização e simulação de conceitos abstratos, relacionando a teoria à prática, podem auxiliar na construção do conhecimento científico e, desta forma confirmamos a afirmativa proposta nesta pesquisa científica.

\section{REFERÊNCIAS}

ABDI, Hervé. Guttman Scaling. In N.J. Salkind (Ed.): Encyclopedia of research design. Thousand Oaks (CA): Sage, 2010.

ALMEIDA, Saulo. Variáveis e Escalas de Medidas. Prof. Saulo Almeida: Medidas em Psicologia, 2014. Disponível em: < https://professorsauloalmeida.com>. Data de acesso: 16 de abril de 2018.

CARRILHO, Manuel Maria. Epistemologia - Posições e Críticas. Lisboa: Fundação Calouste Gulbenkian, 1991.

ESTEBAN, Maria Paz Sandín. Pesquisa qualitativa em educação: fundamentos e tradições. São Paulo: McGraw-Hill, 2010.

GÁRCIA, José M. R. Escalamiento, técnica de Guttman. Proclapar: Sicometría y Estadística, 2013. Disponível em: <http://www.proclapar.com>. Data de acess: 16/04/2018.

GUTTMAN, Louis A. A basis for scaling qualitative data. American Sociological Review, vol. 9, $\mathrm{n}^{\circ}$ 2, abril, p.139-150, 1944.

GUTTMAN, Louis A. The basis for scalogram analisys. In: Stouffer Samuel A. Measurement and prediction. New York: Princeton University Press, 1950. 


\section{REVISTA REAMEC}

Revista ta Rede Amazonitica de Eduraçäo

em Ciências e Matemática
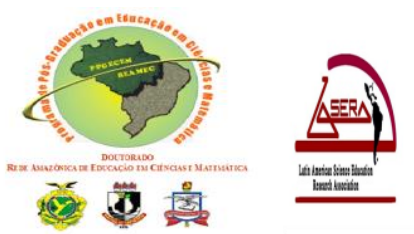

GUTTMAN, Louis A. The Cornell technique for scale and intensity analysis. Educational and Psychological Measurement, vol. 7, no 2, julio, p.247-279, 1947.

KUHN, T. S. A estrutura das revoluções científicas. 9. Ed. São Paulo: Perspectiva, 2006.

MORAN, José M. Desafios que as tecnologias digitais nos trazem. In: MORAN, José M. Novas tecnologias e mediação pedagógica. Campinas, São Paulo: Papirus, 2013.

NUNES, Daniella P. Demanda assistencial de pessoas idosas no município de são Paulo: necessidade de cuidado e utilização dos serviços de saúde. 2015. 152f. Tese (Doutorado) . Escola de Enfermagem Universidade de São Paulo, 2015.

PRENSKY, Marc. Digital Natives, Digital Immigrants. On the Horizon, NCB University Press, Vol. 9, No 5, outubro 2001. Disponível em: < http://marcprensky.com/articles-in-publications >. Data de acesso: 05 de março de 2016.

PRETTO, Nelson D. L. Linguagens e Tecnologias na Educação in CADAU, Vera M. Cultura, Linguagem e Subjetividade no Ensinar e Aprender. Rio de Janeiro: DP\&A Editora, 2017.

TORRES, Michelle V. Hierarquização de incapacidade funcional de idosos no Município de São Paulo: uma análise longitudinal (Estudo SABE - Saúde, Bem-estar e Envelhecimento). 2009. 96f. Dissertação (Mestrado em Saúde Pública). Faculdade de Saúde Pública - Universidade de São Paulo, 2009. 